\title{
Da intersubjetividade husserliana à solidariedade gadameriana: considerações sobre a vida compartilhada
}

\section{From Husserlian intersubjectivity to Gadamerian solidarity: considerations about shared life}

\author{
Luciane Luisa Lindenmeyer ${ }^{1}$ \\ Universidade do Vale do Rio dos Sinos - UNISINOS \\ lucianelindenmeyer@gmail.com \\ https://orcid.org/0000-0002-6386-9171
}

\section{RESUMO}

Este artigo investiga as correspondências filosóficas entre as noções de intersubjetividade husserliana e solidariedade gadameriana. Esses conceitos representam a dimensão de experiências compartilhadas que constituem tanto a fenomenologia de Husserl quanto a hermenêutica filosófica de Gadamer. É possível mapearmos as influências de Husserl no projeto gadameriano através da tradição que hoje conhecemos como filosofia fenomenológico-hermenêutica. A intersubjetividade e a solidariedade representam o momento em que o outro é integrado seja nas nossas experiências imediatas e fenomenológicas do mundo, seja na nossa relação cotidiana com as outras consciências, compartilhando responsabilidades mútuas a fim de que as relações coletivas sejam efetivadas na prática. Assim, podemos considerar também que a solidariedade está diretamente ligada à intersubjetividade fenomenológica. Sob essas condições, consideraremos a intersubjetividade como um nível filosófico para o estabelecimento da solidariedade. Essas duas dimensões são, antes de tudo, condições para pensarmos a vida compartilhada.

\footnotetext{
${ }^{1}$ Doutoranda em Filosofia na Universidade do Vale do Rio dos Sinos.
} 
Palavras-chave: Intersubjetividade. Solidariedade. Fenomenologia. Hermenêutica filosófica.

\begin{abstract}
This paper investigates philosophical correspondences between Husserlian intersubjectivity and Gadamerian solidarity. These concepts represent the dimension of shared experiences that creates both Husserl's phenomenology and Gadamer's hermeneutic heritage. It is possible to map Husserl's influences on the Gadamerian project through the tradition we now know as phenomenological-hermeneutic philosophy. Intersubjectivity and solidarity represent the moment when the other is integrated either in our immediate and phenomenological experiences of the world, or in our daily relationship with other consciousnesses, sharing mutual responsibilities so that collective relations can be realized in practice. Thus, we can also consider that solidarity is directly linked to phenomenological intersubjectivity. Under these conditions, we will consider intersubjectivity as a philosophical level for the establishment of solidarity. These two dimensions are first and foremost conditions for thinking about shared life.
\end{abstract}

Keywords: Intersubjectivity. Solidarity. Phenomenology. Philosophical hermeneutics.

\title{
1. Introdução
}

Que a fenomenologia husserliana tenha influenciado a hermenêutica filosófica de Hans-Georg Gadamer, os estudiosos da filosofia hermenêutica-filosófica provavelmente não objetariam. Ainda porque essa influência é mencionada em formato de agradecimento já na sua obra mais consagrada Verdade e método. Gadamer, ao tratar de um dos elementos centrais de seu pensamento, a experiência estética, considera que: "temos de agradecer, antes de mais nada, à crítica fenomenológica aplicada à psicologia e a teoria do conhecimento do séc. XIX a liberação dos conceitos que impediam uma adequada compreensão do ser estético" (GADAMER, 1997, p. 105). A experiência estética é justamente o elemento que funciona como o critério claro de diferenciação entre a sua proposta de hermenêutica e o modelo de hermenêutica clássica precedente.

Essa menção refere-se precisamente ao que estava no cerne da preocupação de Husserl no momento da fundação de seu projeto da fenomenologia, a crítica ao 
positivismo e ao psicologismo. Essa crítica funda a fenomenologia como ciência das essências ou dos fenômenos, de modo que não se pode mais considerar o clássico dualismo filosófico entre consciência interna e realidade externa. Essa era a equivocada perspectiva de teorias psicologistas como a de Descartes. Husserl pretendia situar a problemática de seu pensamento em uma nova orientação, a orientação fenomenológica ou intencional, a partir da qual a fenomenologia tem como objeto de interesse o aparecimento dos fenômenos para a consciência intencional, que é justamente a consciência já na sua relação indissociável com o mundo transcendente.

A partir dessas condições, as essências, sempre atribuídas ao conhecimento fenomenológico, não correspondem unicamente à finalidade de seu método, uma vez que “[...] a essência não é a meta, que ela é um meio, que nosso engajamento efetivo no mundo é justamente aquilo que é preciso compreender e conduzir ao conceito" (MERLEAUPONTY, 1999, p. 11). Nesse sentido, as essências são as mediadoras entre a consciência e o mundo e possuem uma dimensão compartilhada. Não é possível falarmos de essência a partir de vivências conscientes unicamente subjetivas, mas sim intersubjetivas.

É através dessa perspectiva intersubjetiva que a subjetividade que caracteriza o pensamento fenomenológico, a subjetividade transcendental, contém em si mesma o mundo circundante (Umwelt) e, consequentemente, as demais subjetividades. Sobre essa correlação entre subjetividade transcendental e intersubjetividade Husserl questiona, nas suas Meditações cartesianas, após falar sobre a redução do mundo à consciência: "Como ficamos, porém, com os outros ego, que não são, de todo, uma simples representação e algo representado em mim, simples unidades sintéticas de possível confirmação em mim, mas antes, segundo o seu sentido, precisamente outros?" (HUSSERL, 2013, p. 127).

A hermenêutica filosófica de Hans-Georg Gadamer absorve, em grande medida, a constituição de uma experiência fenomenológica que ilustra alguns de seus conceitos centrais como o de "fusão de horizontes". A experiência fenomenológica, uma vez feita a crítica ao positivismo e ao psicologismo, realiza-se como vinculação direta do sujeito com o mundo. Se já não dispomos das interferências dos preconceitos psicológicos ou da pretensa análise neutra e objetiva da realidade, então podemos contar com o aparecimento do mundo como ele aparece para a consciência, ou ainda, a partir das "coisas mesmas". É como se a proposta de uma depuração dos pressupostos filosóficos de toda vivência de consciência que caracteriza propriamente a experiência fenomenológica abrisse os 
caminhos para a fundação de uma hermenêutica filosófica, e aqui é importante destacar também a mediação do modelo de fenomenologia heideggeriana, para a possibilidade de uma compreensão efetivamente hermenêutica do mundo em que toda subjetividade é parte integrante.

O tema da solidariedade é abordado por Gadamer de maneira esparsa em textos posteriores à Verdade e método. Ainda assim, é possível encontrarmos as condições filosóficas relevantes para o tratamento da solidariedade como um elemento essencial para a vida compartilhada em sociedade sob a própria dimensão prática que compõe a hermenêutica filosófica de Gadamer. Em Husserl, o tema da vida compartilhada é mais claramente identificável no período final de suas produções filosóficas, no qual a intersubjetividade é novamente apresentada, agora, sob a perspectiva do seu Lebenswelt (mundo da vida).

O propósito central desta investigação é apresentar as condições fenomenológicas presentes na intersubjetividade husserliana, de modo que elas sejam tomadas como um nível filosófico necessário para que possamos considerar a solidariedade gadameriana na sua própria dimensão da vida compartilhada. Apresentarei correspondências filosóficas entre esses dois conceitos centrais para este trabalho, de modo a indicar como a solidariedade gadameriana é constituída como uma experiência compartilhada propriamente fenomenológica.

O movimento filosófico a ser explorado aqui é o da fenomenologia-hermenêutica, de modo que consideramos as condições da intersubjetividade husserliana como um primeiro estágio, aquele caracterizado pela análise dos atos puros de consciência que significam as nossas experiências em um mundo compartilhado até o momento em que passamos ao nível da práxis da hermenêutica filosófica, aqui efetivada pela solidariedade como elemento central para a vida compartilhada.

\section{Intersubjetividade como teoria transcendental do mundo objetivo}

A intersubjetividade constitui, na fenomenologia husserliana, parte da significação do mundo como fenômeno, isto é, como sendo aparente para a consciência. No entanto, esse fenômeno diferencia-se dos demais fenômenos do mundo, já que o outro não possui as mesmas condições essenciais de um objeto ordinário ou instrumental. Esse 
fenômeno aparece através dos corpos animados que compõem as outras consciências, a partir dos quais temos a experiência mediata das outras subjetividades. É a partir dessas questões que a fenomenologia, fundada como uma teoria "idealista" aborda o problema do outro, de modo que pela noção de intersubjetividade transcendemos a nossa própria subjetividade em direção à existência consciente também dos outros, e nunca podemos reduzir as demais subjetividades às nossas próprias vidas conscientes.

Mesmo que a constituição da intersubjetividade transcendental, na fenomenologia de Husserl, seja fundada a partir de uma análise nos moldes cartesianos, na qual partimos de nossa subjetividade para em seguida descobrirmos as demais consciências também existentes, o elemento que garante essa existência é a própria condição de que o mundo em si existe independentemente de que tenhamos consciência dele ou que façamos juízos sobre ele. Esse é o ponto em que podemos pensar na passagem de um modelo idealista transcendental para a efetividade do que Husserl chama de intersubjetividade transcendental, i.e., o momento em que a fenomenologia trata da comunidade compartilhada, ou universal, de mônadas.

A fenomenologia husserliana tem como interesse investigativo os diferentes significados das vivências de consciência. A vivência consciente que temos de outras consciências se dá a partir dessas modalidades de mônadas individuais que estão inseridas em um ambiente compartilhado, que Husserl chama de mundo da vida (Lebenswelt). Embora Husserl já considerasse a noção de intersubjetividade nas suas conferências intituladas Sobre fenomenologia da intersubjetividade ${ }^{2}$ e também nas suas famosas Meditações cartesianas, a noção de "mundo da vida", que se refere ao mundo concreto das vivências de consciência ou das experiências vividas, só aparece em seus escritos já no período final de suas produções, representado pela Crise da humanidade europeia e a filosofia. É nessa dimensão do mundo da vida que estão contidas as nossas experiências mais imediatas e cotidianas, as quais não podem ser reduzidas aos resultados das análises científicas. A fenomenologia é justamente o método filosófico que aproxima essas experiências ordinárias de estabelecimento de sentidos e de significados instituídos para além da objetividade matemática tão cara ao pensamento científico.

\footnotetext{
${ }^{2}$ Zur Phänomenologie der Intersubjektivität, publicadas em três volumes referentes aos períodos de 19051920, 1921-1928 e 1929-1935, ainda sem tradução para o português.
} 
É sob esse horizonte fenomenológico que Husserl trata da noção de intersubjetividade que caracteriza o seu pensamento e que é, ela mesma, não redutível à análise empírica da psicologia como ciência natural. A mútua relação entre as mônadas é mediada pelo mundo da vida que não está situado, pela perspectiva da orientação fenomenológica, na dimensão da vida natural. Afinal, o método fenomenológico é instituído a partir da suspensão do mundo natural, no sentido de que esse mundo existe antes mesmo de pensarmos sobre ele, mas que a sua contingência factual não interessa à análise propriamente fenomenológica. É claro que experienciamos sensitivamente o mundo através da percepção e de todos os nossos sentidos de maneira imediata e irrefutável. No entanto, as experiências imediatas não chegam a ser instantaneamente conceitualizadas, a não ser no caso de empregarmos uma mudança atencional que permita que a intuição da realidade fique cada vez mais clara e vivificada por meio de recordações, de maneira que a efetividade de nossas experiências de consciência do mundo está também ligada ao tempo. Assim, a percepção sensível é apenas privilegiada como fonte dos dados originários da vivência de mundo, mas não o elemento exclusivo para a síntese de significado desse mundo. Podemos afirmar, nesse sentido, que a estrutura fenomenológica de nossas experiências do mundo da vida está diretamente vinculada à temporalidade.

Uma das mais importantes asserções husserlianas que caracterizam o mundo da vida como um mundo irredutível ao mundo puramente natural refere-se à definição de que o mundo da vida "não está para mim aí como um mero mundo de coisas, mas, em igual imediatez, como mundo de valores, como mundo de bens, como mundo prático" (HUSSERL, 2006, p. 75). Assim, acabamos por estabelecer relações de valor, seja com as "meras coisas", seja com os outros seres humanos com quem compartilhamos a existência, sendo esses indivíduos “meus 'amigos' ou 'inimigos', meus 'subordinados' ou 'superiores', ‘estranhos' ou 'parentes', etc.” (HUSSERL, 2006, p. 75).

Ao experienciarmos o mundo como fenômeno através da intencionalidade, i.e., da relação indissociável entre consciência e mundo, os significados que daí surgem estão contidos nessa mesma relação, ou ainda, nos próprios atos significantes. Os atos intencionais referentes às nossas interações sociais são, justamente, os denominados atos sociais. Podemos falar de um mundo especificamente social, na medida em que nossa consciência assim constitui esse significado intencionalmente, e é nesse nível que 
podemos considerar a dimensão compartilhada do mundo através de uma intencionalidade comum a todas as mônadas ou consciências. Nesse sentido, podemos, inclusive, fazer o uso da primeira pessoa do plural, nós, para nos referirmos a experiências públicas.

Como vimos, é no mundo da vida que acontecem todas as experiências intencionais da consciência, inclusive dos objetos puramente materiais, mas é também esse mesmo mundo da vida que media os atos sociais e as relações entre indivíduos que se referem a esses atos. É, portanto, no próprio mundo da vida, em oposição àquele modelo de mundo que matematiza a vida, o das ciências naturais, que está situado todo o horizonte do que Husserl chama de "aí-para-mim dos outros" (HUSSERL, 2013, p. 130). É exatamente nesse sentido que o mundo da vida fenomenológico é pré-científico.

Em termos husserlianos, na medida em que percorremos os caminhos da pura subjetividade transcendental em direção à objetividade do mundo circundante, passamos para a perspectiva da fenomenologia noemática, i.e., ao tipo de análise que consiste na dimensão própria da estrutura de significado do mundo e que institui, por sua vez, a própria subjetividade. Isso quer dizer que a subjetividade é também constituída pelo mundo compartilhado através da sua relação intencional com ele, que é um tipo de relação muito mais originária do que a própria individualidade. A intencionalidade é a estrutura própria da experiência de mundo de toda e qualquer consciência. Portanto, as consciências coexistem no mundo da vida através da mesma estrutura de consciência intencional que é voltada para o que é alheio a cada ego, sejam os objetos, sejam os outros egos, ou "alter-egos”, como considera Husserl. A vinculação entre esses dois elementos se dá a partir de uma reciprocidade, na qual um reconhece o outro sem, no entanto, confundirem-se.

Sob essas condições, as próprias idealidades que compõem a fenomenologia husserliana pressupõem a intersubjetividade no sentido de que o conhecimento filosófico só pode ser efetivamente realizado na estrutura compartilhada do mundo da vida. Desse modo,

\footnotetext{
Surge, assim, uma humanidade especial e uma profissão especial com a nova criação (Leistung) de uma cultura. O conhecimento filosófico do mundo origina não só esses resultados especiais, mas um comportamento que repercute de imediato em todo resto da vida prática, com todos os seus fins e sua atividade, ou seja, os fins da tradição histórica, na qual somos engendrados e daí adquirem seu valor (HUSSERL, 2008, p. 73).
} 
Husserl considera que é apenas através do compartilhamento do conhecimento filosófico, o qual possui em si mesmo um caráter de universalidade, que poderíamos fundar uma comunidade onde "se cultivam os valores puros e incondicionais da verdade como um bem comum" (HUSSERL, 2008, p. 74). Assim, a filosofia representa um caminho para novas possibilidades em relação ao que já é tradição, na medida em que mais e mais indivíduos tomem conhecimento dos preceitos filosóficos a partir de uma atitude constante de superação do realismo natural e ingênuo. Essa relação conflituosa entre filosofia e tradição resulta, portanto, em duas posturas distintas em relação ao que já é preestabelecido: “Ou os valores tradicionais são totalmente rejeitados ou se assume seu conteúdo a um nível filosófico e, assim, recebe uma forma nova no espírito da idealidade filosófica" (HUSSERL, 2008, p.75).

A análise husserliana da noção de tradição, no interior da qual acontecem as experiências intersubjetivas do mundo da vida, está vinculada com a sua concepção de que o filosofar corresponde a uma "tarefa infinita" (HUSSERL, 2008, p.78). Nesse sentido, contamos com o horizonte da tradição que antecede a nossa época de existência, mas é apenas pelo conhecimento filosófico como constante reflexão do mundo que uma humanidade propriamente autêntica pode ser realizada.

No interior da noção de intersubjetividade husserliana está a concepção de que só podemos experienciar as demais subjetividades através de suas realidades corpóreas, de modo que "A partir desta vivência de homogênea alteridade recíproca se constitui a comunidade humana, apercebendo-me, simultaneamente, de minha própria humanidade" (HUSSERL, 2008, p.35). Assim, mesmo que todos os sujeitos estejam inseridos nessa realidade objetiva do mundo, compartilhamos também um mundo de valores. A ciência é apenas uma das modalidades de atividades práticas. Uma sociedade reduzida à matematização da vida estaria por desconsiderar as outras dimensões práticas da vida coletiva, como a ética, por exemplo.

Ao considerar a própria relação da subjetividade com a intersubjetividade a partir de um movimento de constituição originária de sentido irredutível às explicações puramente científicas, Husserl apresenta o desenvolvimento intencional das nossas experiências de mundo. Nesse sentido,

Todos os estádios e estratos pelos quais se entrelaçam as sínteses intencionais que se estendem de sujeito a sujeito formam uma unidade universal da síntese. Por eles surge o universo representativo, o mundo 
que e tal como viva e concretamente é dado (e como o que é pré-dado para toda a práxis possível) (HUSSERL, 2012, p. 137).

É em nível intersubjetivo que estão, portanto, situados fillosoficamente o que Husserl chama de "horizontes mais vastos de explicitação" (2012, p. 136), sem os quais não há um completo sistema de doação de sentido do mundo da vida. Através da relação fenomenológica entre ego e alter-ego, chegamos à dimensão da

Sociabilidade universal (a "humanidade", neste sentido, como espaço de todos os eus-sujeitos. Mas é claro que a síntese da intersubjetividade diz respeito a tudo: o mundo da vida intersubjetivamente idêntico para todos serve como "índice" intencional para as multiplicidades de aparições que, ligadas na síntese intersubjetiva são aquilo que, através de todos os eus-sujeitos (e não porventura cada um meramente por meio das suas multiplicidades individualmente próprias), está orientado para o mundo comum e para as suas coisas, como campo de todas as atividades etc. ligada no nós geral (HUSSERL, 2012, p. 141).

\section{Solidariedade enquanto acordo profundo e coletivo}

Ao considerarmos a solidariedade gadameriana precisamos passar para o nível da práxis pressuposta para a sua hermenêutica filosófica. Essa dimensão prática que caracteriza propriamente a hermenêutica contemporânea remonta ao pensamento aristotélico, em especial, através da noção de phronesis, com a qual a hermenêutica filosófica é constituída por um novo modelo de racionalidade. Nesse sentido, o conceito de solidariedade caracteriza a própria dimensão da compreensão dialética da hermenêutica filosófica, na qual está imbricado também o uso compartilhado da linguagem. A noção de solidariedade é pensada por Gadamer, coincidentemente ou não, ao mesmo tempo em que ele abandona o uso da noção de tradição, em textos posteriores à Verdade e método. Essa substituição conceitual chega a ser até mesmo apontada como um “deslize quase imperceptível” (LAWN, 2010, p. 139).

A noção de tradição representa, em grande medida, a própria dimensão da vida compartilhada que está presente na hermenêutica filosófica como elemento que ilustra a sua abordagem prática e, consequentemente, compõe a crítica gadameriana aos modelos filosóficos subjetivistas. Em especial, àqueles modelos linguísticos que propunham unicamente um tipo de linguagem privada, a partir da qual a subjetividade realiza designações sobre a realidade. Como se a linguagem fosse estática sem poder constituir, 
ela mesma, o mundo a partir de novas estruturas semânticas. Na hermenêutica filosófica, "Toda linguagem falada apresenta-se apenas como a palavra que é dita a alguém, como a unidade de discurso que cria comunicação entre os homens e constrói solidariedade" (GADAMER, 2002, p. 28).

A abordagem gadameriana sobre os usos compartilhados da linguagem ilustra perfeitamente a inserção da subjetividade na vida coletiva, sendo a própria linguagem um dos tipos de acordos comuns realizados entre todos os integrantes de uma mesma comunidade. Nesse sentido, a linguagem é também o elemento representante do processo dialético que compõe a hermenêutica filosófica e que dinamiza a experiência de mundo através das diferentes fusões de horizonte que realizamos com o mundo e com os outros que estão igualmente inseridos nele. As fusões mencionadas são constituídas pela vinculação indissociável, seja entre a subjetividade e a objetividade do mundo, seja entre subjetividade e intersubjetividade. Essa última modalidade de fusão é privilegiada justamente pela centralidade do diálogo como modelo estrutural para a compreensão hermenêutica do mundo. É exatamente sob essa perspectiva que consideramos aqui também a intersubjetividade fenomenológica, a partir da qual reduzimos a objetividade pura do mundo, e mesmo a nossa própria subjetividade transcendental para considerarmos também a existência do outro.

Gadamer situa tanto a linguagem como a solidariedade no horizonte comunitário, onde são constituídos os acordos mediadores de conflitos inerentes à própria dinâmica da coexistência coletiva. A íntima relação entre linguagem e solidariedade que daí decorre está no sentido de que "[...] para Gadamer, o significado é possível e compreensão e linguagem são atualizadas porque certas solidariedades estão no centro de todas as nossas empresas hermenêuticas e interpretativas" (LAWN; KEANE, 2011, p. 133)³. Essa é, portanto, a centralidade do conceito de solidariedade para o movimento dialógico de seu projeto de hermenêutica filosófica. Projeto que só pode ser efetivado a partir da relação fenomenológica entre subjetividade e intersubjetividade, de modo que o que era antes

3 “[...] For Gadamer meaning is possible and understanding and language are actualized because certain solidarities are at the heart of all our interpretative, hermeneutical enterprises" (LAWN; KEANE, 2011, p. 133). Tradução da autora. 
alheio à esfera da subjetividade transcendental deixa de sê-lo e torna-se parte do fenômeno-mundo que é manifesto intencionalmente para a consciência.

Ao reconhecer intersubjetivamente a existência de outras consciências e subjetividades alheias à nossa própria existência consciente, mas que são elas mesmas semelhantes a mim através de sua realidade psicofísica e corporal, alcançamos um nível de impessoalidade fenomenológica necessária para a própria noção de solidariedade como acordo profundo e coletivo, de maneira que superamos assim a tendência de termos maiores simpatias pelo que nos é familiar e próximo, e passamos a considerar também o que nos é diverso. Essa impessoalidade transpassa a noção de horizonte importante tanto para a fenomenologia de Husserl quanto a hermenêutica filosófica de Gadamer. Ao referenciar o conceito de horizonte husserliano, Gadamer considera a sua pertinência no sentido de que "Um horizonte não é uma fronteira rígida, mas algo que se desloca com a pessoa e que convida a que se continue penetrando" (1997, p. 373).

Há o horizonte fenomenológico do mundo da vida que funda a intersubjetividade na objetividade da vida compartilhada entre as subjetividades. Da mesma forma, a solidariedade gadameriana só é possível com a efetividade da fusão entre os horizontes individuais que integram a totalidade de uma mesma vida compartilhada. $\mathrm{O}$ acordo profundo pressuposto para as relações solidárias é, na hermenêutica filosófica, sinônimo de fusão de horizontes e nesse horizonte do mundo compreensivo que é compartilhado alcançamos fenomenologicamente a sua abertura constante para a impessoalidade das relações com o outro. Assim, a solidariedade como acordo coletivo possui profundidade também no sentido de que

A fusão de horizontes é aparentemente cega para as fronteiras nacionais e temporais. Desde que o processo hermenêutico envolva universalidade, todo entendimento, qualquer que seja o fundo, participa do círculo hermenêutico da incompletude, da parte e todo (LAWN; KEANE, 2011, p. 133).

O horizonte hermenêutico é constituído e expandido, assim, não apenas pelas fusões compreensivas realizadas entre os indivíduos e a tradição, mas também através da

\footnotetext{
4 "The fusion of horizons is seemingly blind to national and temporal boundaries. Since the hermeneutic process involves universality, all understanding, whatever the cultural background, participates in the hermeneutic circle of incompleteness, of part and whole" (LAWN; KEANE, 2011, p. 133). Tradução da autora.
} 
relação de solidariedade mútua entre os próprios indivíduos, que perpassa também a dimensão ética intrínseca ao movimento dialético da linguagem. Assim, a hermenêutica filosófica está às voltas com uma racionalidade discursiva, no interior da qual estão os componentes filosóficos de uma responsabilidade ética. Essa responsabilidade é pressuposta para todas as relações de solidariedade que efetivam o modelo hermenêutico de uma racionalidade prática.

No contexto da hermenêutica filosófica, linguagem e ética estão intimamente vinculadas, no sentido de que é sempre pressuposta uma racionalidade discursiva que é, ela mesma, dialética nos moldes platônicos e que assim

É mais preciso, portanto, dizer que não há filosofar moral na tese de habilitação
de Gadamer. Mas com a afirmação de que a própria dialética é ética, se segue
que toda discussão sobre a estrutura da argumentação dialética também é uma
discussão sobre como levar a vida ética. Portanto, a tese da habilitação pode
ser lida não apenas do ponto de vista de sua contribuição para a filosofia da
linguagem, mas também de sua contribuição para o pensamento ético
(SULLIVAN, 1989, p. 121). ${ }^{5}$

O horizonte da solidariedade perpassa a dinâmica compreensiva prática da hermenêutica filosófica, i.e., a solidariedade, como acordo profundo, é justamente o elemento que possibilita o movimento dialético discursivo, composto tanto pelas perguntas quanto pelas respostas. Esse é o procedimento do diálogo hermenêutico por excelência. Nessa modalidade de diálogo, a solidariedade equivale ao horizonte de realização comunicativa, sem o qual a compreensão não seria possível.

A solidariedade, enquanto vinculada à noção de tradição, possibilita o movimento de abertura para novos horizontes que caracteriza a compreensão propriamente dialógica, e é exatamente por ser dialógica que a compreensão hermenêutica só pode ser realizada com a presença do outro. Sob essas condições, o acordo solidário, comum e profundo entre os indivíduos não é e não poderia ser um acordo estático, que faria referência interessada apenas nos acontecimentos do passado. A solidariedade hermenêutica é, como

\footnotetext{
${ }^{5}$ Tradução da autora. "It is more accurate, therefore, to say that there is no moral philosophizing in Gadamer's habilitation thesis. But with the claim that dialectics itself is ethical, if follows that all discussion of the structure of dialectical argumentation is also a discussion of how to lead the ethical life. Hence the habilitation thesis can be read not simply from the point of view of its contribution to language philosophy but also for its contribution to ethical thinking" (SULLIVAN, 1989, p. 121).
} 
temos insistido, uma modalidade de acordo, mas um acordo para uma vida compartilhada que é também direcionado para o futuro. Essa é a mesma dinâmica em que o processo de interpretação acontece, sempre através de um horizonte de novas possibilidades de significado.

Ao contrário do que pode parecer numa primeira consideração do conceito de tradição gadameriana, ela não condena a hermenêutica filosófica a um tipo de teoria filosófica aos moldes conservadores, tendo em vista a sua projeção para as experiências compartilhadas futuras, de maneira que a tradição "é o conduto através do qual fluem os elementos centrais da vida social, conectando passado ao presente e ao futuro" (LAWN, 2010, p.140). É através da adoção do conceito de solidariedade que a hermenêutica filosófica gadameriana adquire o caráter de uma hermenêutica aplicada, tendo também como elementos compreensivos a linguagem e a história. Os modelos de solidariedade já existentes na tradição podem ser acessados através da linguagem. Esse acesso é o que caracteriza o esforço propriamente hermenêutico de compreensão do mundo e do outro, mas essa volta ao passado, ao ser constituída dialeticamente, possui um caráter antidogmático, não sendo, portanto, uma retomada de princípios universais que regrariam a convivência humana.

\section{Considerações finais}

Como vimos até aqui, a fenomenologia husserliana é caracterizada como crítica à matematização do mundo da vida, em especial no período final de seu desenvolvimento teórico, que é resultado da hegemonização do método específico das ciências empíricas ou do naturalismo. O naturalismo desconsidera as condições históricas a que a própria produção científica está integrada, e reivindica para si uma neutralidade de análise que o afasta das nossas experiências mais cotidianas. Assim, ao considerarmos os limites do método positivo de aproximação da realidade, a fenomenologia éo método por excelência que nos permite considerar a dimensão da vida compartilhada com as outras subjetividades, em especial com o uso do conceito de intersubjetividade. É através da dimensão da intersubjetividade que podemos perceber a existência de outras subjetividades corpóreas que também fazem parte do mundo da vida.

É justamente através da perspectiva de um modelo de intersubjetividade fenomenológica que podemos traçar as condições filosóficas para a solidariedade 
enquanto comprometimento mútuo entre subjetividades que compõem a vida compartilhada do mundo. Ao suspendermos o mundo natural dos objetos ordinários para concentrarmos a atenção nos outros ego como sendo um "alter-ego" que me é idêntico a partir da sua realidade psicofísica alcançamos um grau de impessoalidade para as relações necessárias à vida compartilhada. Essa impessoalidade é também um elemento crucial para a própria noção de solidariedade hermenêutica, de modo que os acordos de responsabilidade vão sendo expandidos, na medida em que a própria tradição seja integrada a novas perspectivas filosóficas.

O horizonte intersubjetivo pressuposto como uma etapa filosófica da solidariedade possibilita a fusão entre subjetividades e, consequentemente, a produção de novos significados de mundo e, mesmo, de novos acordos de solidariedade. É a partir da intersubjetividade que a própria compreensão hermenêutica é possível, já que é propriamente na dimensão da vida compartilhada que a compreensão é realizada como um modo de ser de nossa presença no mundo da vida. A relação hermenêutica com o outro, fundada a partir da crítica de Gadamer ao modelo de racionalidade cientificista que dissocia a subjetividade e o mundo, é caracterizada por uma perspectiva filosófica especificamente dialógica que privilegia as interações linguísticas. Essas interações não podem acontecer se as relações intersubjetivas não forem mediadas pelas relações de solidariedade, enquanto acordos profundos.

A intersubjetividade, como teoria transcendental do mundo, representa a crítica fenomenológica às teorias subjetivistas e posiciona a análise fenomenológica do mundo na dimensão compartilhada do mundo da vida, no sentido de que

\footnotetext{
O eu então já não mais é uma coisa isolada ao lado de outras coisas similares dentro de um mundo dado de antemão; a exterioridade e a justaposição dos eus pessoais cede lugar a uma relação íntima entre os seres que são um no outro e um para outro (HUSSERL, 2008, p. 87).
}

Essa relação que funda o horizonte intersubjetivo do mundo da vida e a própria solidariedade que possibilita a renovação de acordos em comunidade são conceitos mediados pela carga de historicidade que define, em grande medida, a própria tradição da filosofia fenomenológica-hermenêutica. Tradição filosófica que assume a crítica ao objetivismo presente no método da racionalidade moderna que resultou em um empecilho para essa renovação: uma consciência científica exagerada. 
Ao problematizar a aproximação da subjetividade com a realidade do mundo através da intersubjetividade e das relações de solidariedade situamos o mundo da vida também na perspectiva de sujeitos que são, eles mesmos, históricos e cercados por valores. Portanto, eles só podem ser compreendidos através de saberes que estão para além do conhecimento puramente científico. Essa abordagem fenomenológicahermenêutica da vida compartilhada possibilita a reflexão não apenas sobre o passado, mas apresenta condições para pensarmos o futuro. Assim, somos capazes de aprimorar a vida em sociedade a partir de uma práxis que não equivale estritamente ao experimento científico, mas que expande a aproximação com o real através do uso ponderado de uma racionalidade prática. Consequentemente, atribuímos novas abordagens e significados para a tradição que perpassa o mundo da vida.

A intersubjetividade fenomenológica, como elemento que constitui a comunidade humana através do reconhecimento recíproco entre as mônadas ou subjetividades, e a solidariedade hermenêutica, como o tipo de acordo coletivo que torna viável as relações de responsabilidade, e mesmo o uso da linguagem nelas implícitos, privilegiam, assim, o mundo da vida na sua dimensão da coexistência, da solidariedade ou alteridade em um horizonte original de um mundo comum a todos. Entretanto, esse mundo comunitário não nos é dado de imediato, mas ele é cada vez mais expandido, de modo que a comunidade humana vai sendo amplificada através de novos acordos profundos de solidariedade e na medida em que o sujeito constitui a sua própria humanidade individual.

\section{Referências bibliográficas}

GADAMER, H. G. Reason in the Age of Science. Translated by Frederick G. Lawrence. MIT Press Publishing, 1998.

. Verdade e método: traços fundamentais de uma hermenêutica filosófica. Trad. Flávio Paulo Meurer. $1^{\text {a }}$ Edição. Petrópolis: Editora Vozes, 1997.

- Verdade e método II: complementos e índice. Trad. Ênio Paulo Giachini. Petrópolis, RJ: Vozes, 2002.

HUSSERL, E. A crise das ciências europeias e a fenomenologia transcendental: uma introdução à filosofia fenomenológica. De acordo com a Husserliana VI. Trad. Diogo Falcão Ferrer. $1^{a}$ Ed. Rio de Janeiro: Forense Universitária, 2012. 
. A crise da humanidade europeia e a filosofia. Trad. Urbano Zilles. $3^{\text {a }}$ Ed. Porto Alegre: EDIPUCRS, 2008.

Ideias para uma fenomenologia pura e para uma filosofia fenomenológica: introdução geral à fenomenologia pura. Trad. Márcio Suzuki. Aparecida SP: Ideias e letras, 2006.

. Meditações cartesianas e Conferências de Paris: de acordo com a Husserliana I. Trad. Pedro M. Alves. $1^{\text {a }}$ Ed. Rio de Janeiro: Forense, 2013.

. Zur Phänomenologie der Intersubjektivität. Texte aus dem Nachlass. Erster Teil: 1905-1920. The Hague, Neatherlands: Martinus Nijhoff, 1973.

. Zur Phänomenologie der Intersubjektivität. Texte aus dem Nachlass. Zweiter Teil: 1921-1928. The Hague, Neatherlands: Martinus Nijhoff, 1973.

.Zur Phänomenologie der Intersubjektivität. Texte aus dem Nachlass. Dritter Teil: 1929-1935. The Hague, Neatherlands: Martinus Nijhoff, 1973.

LAWN, C. Compreender Gadamer. Trad. Hélio Magri Filho. 2 ${ }^{\mathrm{a}}$ Ed. Petrópolis, RJ: Vozes, 2010;

LAWN, C.; KEANE, N. The Gadamer Dictionary. New York: Continuum, 2011.

MERLEAU-PONTY, M. Fenomenologia da percepção. Trad. Carlos Alberto Ribeiro de Moura. 2. ${ }^{a}$ Ed. São Paulo: Martins Fontes, 1999.

SULLIVAN, R. R. Political Hermeneutics: The early thinking of Hans-Georg Gadamer. The Pennsylvania State University Press, 1989.

Recebido em: 08/12/2020 | Aprovado em: 03/02/2021 